This original version of this article is published by Sage Publications, http://www.sagepublications.com, and may be accessed at http://jea.sagepub.com/cgi/content/abstract/25/2/223.

The Journal of Early Adolescence

DOI: $10.1177 / 0272431604274174$

Nickerson, Amanda B. and Richard J.Nagle. "Parent and peer relations in middle childhood and early adolescence." Journal of Early Adolescence 25:2 (May 2005), p. 223-249. Sage

Publications, Ltd, 2005.

\title{
Parent and Peer Attachment in Late Childhood and Early Adolescence
}

Amanda B. Nickerson

University at Albany, State University of New York

Richard J. Nagle

University of South Carolina

This study investigated child and early adolescent relationships with parents and peers within the theoretical framework of attachment. A cross-sectional sample of 279 fourth, sixth, and eighth graders completed two self-report measures assessing attachment to parents and friends. Fourth graders described more trusting and communicative relationships with parents than sixth or eighth graders. Older early adolescents turned to peers to fulfill attachment functions of proximity seeking and safe haven more often than children, although all participants reported that parents primarily served secure base functions. Females reported more trust, communication, and overall attachment to peers than males. Grade, sex, and views of attachment relationships to parents and peers predicted the introduction of friends into the attachment hierarchy. Participants who viewed relationships with parents as less secure were more likely to select peers to fulfill attachment functions. The important and complementary roles of parents and peers and their implications are discussed.

Keywords: attachment; parents; peers; intimacy; transition

The transition in parent and peer relationships from late childhood to early adolescence is a dramatic one. With the onset of early adolescence, there is increased conflict in the parent-child relationship and early adolescents perceive their parents as less supportive (Ammaniti, van Ijzendoorn, Speranza, 223

The research presented in this article is based on the first author's doctoral dissertation. The authors wish to thank the students and the school districts whose participation made thiswork possible. We are also grateful to 
Jennifer Brooks and Elizabeth Zhe for their editorial assistance. Correspondence concerning this article

should be addressed to Amanda Nickerson, Department of Educational and Counseling Psychology, ED 232,

University at Albany-State University of New York, Albany, NY 12222. E-mail: anickerson@ uamail.albany.edu.

Journal of Early Adolescence, Vol. 25 No. 2, May 2005 223-249

\& Tambelli, 2000; Arnett, 1999; Paikoff \& Brooks-Gunn, 1991). Peers

become a greater source of support (Allen \& Land, 1999), with loyalty and

faithfulness in friendship becoming more critical (Berndt \& Perry, 1990;

Damon, 1983). Friendships are an important aspect of early adolescents' quest for autonomy, and they view friendships as domains over which they, not their parents, have control (Mounts, 2001). Friendships also serve as the foundation for later intimate relationships; within friendship, children develop social and emotional competence and experience intimacy in a reciprocal fashion (Furman \&Wehner, 1994; Hartup, 1989; Sullivan, 1953). Supportive friendships, particularly for girls, are positively correlated with school achievement, self-esteem, psychosocial adjustment, and success in subsequent relationships and negatively correlated with school problems, loneliness, identity problems, and depression (Bukowski, Hoza, \& Boivin, 1993; Reis \& Shaver, 1988).

One of the most salient features of early adolescent friendships is the intimacy that develops. Numerous studies have shown that intimacy becomes integral to same-sex friendships in early adolescence (Berndt, 1989; Berndt \& Perry, 1990; Collins \& Repinski, 1994), particularly for girls (Berndt \& Perry, 1990). Although intimacy has traditionally been limited to verbal selfdisclosure, its definition has been expanded to include several other concepts such as spending pleasurable time together, feelings of being understood, love, affection, and validation (Buhrmester, 1990; Reis \& Shaver, 1988). Despite the advances in the friendship literature, there is no coherent, comprehensive, developmental theory of friendship that attempts to explain its influence on children's social, emotional, and behavioral adjustment (Furman, 1993; Newcomb\&Bagwell, 1995). In studying transformations in adolescents' relationships with parents and friends, Collins and Repinski (1994) have suggested that trust, intimacy, closeness, and communication are important constructs to study. These relationship features are central to attachment theory.

It has been suggested that attachment theory serves as a model for the study of friendship (Ainsworth, 1989; Sroufe \& Waters, 1977). Although it has been argued that friendships may be better described as affiliative relationships, serving the function of providing stimulation and pleasure, there is also evidence to suggest that some attachment components are evident in friendships (Hazan \& Zeifman, 1994). Given the theoretical and empirical 
literature indicating that close friendships are relationships in which early adolescents share intimacy and companionship, exploring friendships within the theoretical framework of attachment is justified.

\section{Attachment Theory}

Attachment theory is a well-accepted, empirically validated developmental theory that explains the nature of the parent-child bond. Originally applied to infants and young children, attachment behaviors consist of proximity seeking, safe haven, and secure base. Proximity seeking involves approaching, staying near to, and making contact with the attachment figure. The safe haven function involves turning to the attachment figure for comfort, support, and reassurance in the face of threat or danger. The secure base phenomenon involves the use of the attachment figure as a base from which to engage in exploration (Hazan\&Zeifman, 1994). TheWHOTO is a measure that has been used to operationally define these three attachment components for children, adolescents, and adults (Fraley \& Davis, 1997; Hazan \& Zeifman, 1994). To determine the extent to which the proximity-seeking function is playing a role in attachment, the WHOTO asks about the person with whom the respondent likes spending the most time and the person from whom the respondent does not like to be away from. To assess the safe haven function, the respondent is asked to select the person with whom he or she wants to be when feeling upset and the person who can be counted on for advice. To measure secure base, the WHOTO asks about the person the respondent would like to tell first if something good were achieved and the person that the respondent can always count on (Fraley \& Davis, 1997).

An impressive body of literature indicates that secure attachment relationships are associated with consistent and long-term benefits for psychological well being. Longitudinal studies show that children with histories of secure attachment patterns are more competent, emotionally healthy, self-confident, and socially skilled than anxiously attached children (Elicker, Englund, \& Sroufe, 1992). A growing number of researchers have become interested in attachment in adolescence and adulthood (Bartholomew, 1993; Collins \& Feeney, 2000; Fraley\&Shaver, 2000; Rice, 1990) and have proposed that the parent-child attachment relationship serves as a model for all close relationships (Ainsworth, 1989; Hazan \& Shaver, 1987, 1994). Individual attachment patterns relate to peer and romantic relationships in adolescence, and attachment security is correlated with social competence and interpersonal functioning (Allen \& Land, 1999; Black \& McCartney, 1997; Rice, 1990) and inversely correlated with antisocial behavior (Marcus \& Betzer, 1996). Among older adolescents and young adults, security of attachment to parents is also related to emotional functioning, social competence, a smoother balance of autonomy and attachment, problem-solving abilities, and life satisfaction (Cotterell, 1992; Rice, 1990). Even in adulthood, differences in attachment behaviors are linked to social functioning, with insecurely attached individuals having more interpersonal difficulties (Bartholomew, 
1993; Crowell, Fraley, \& Shaver, 1999).

It has been posited that proximity seeking, safe haven, and secure base remain central throughout development, yet change in form, thus resulting in several differences between children's and adults' attachment relationships (Hazan \& Shaver, 1994;Weiss, 1986, 1994). Adult attachment relationships differ from infant-parent attachment in that they are reciprocal, with both members of the dyad being providers and recipients of care. Another difference in the attachment relationship is that it is transformed from external, observable interactions to internally represented beliefs and expectations, where felt security becomes central (Sroufe\&Waters, 1977). In addition, the infant's primary attachment figure is the parent, whereas the adult's primary attachment figure is usually either a close friend or a romantic partner. The safe haven function also differs for infants and adults. For example, infants primarily seek contact with a parent to reduce anxiety and distress, whereas adults seek out an attachment figure to reduce distress, offer comfort, or engage in sexual relations. It has been hypothesized that this fundamental change in the organization of the attachment system occurs during adolescence (Allen \& Land, 1999).

\section{The Role of Peers in the Attachment Hierarchy}

Recognizing the importance of close friends for early adolescents, theorists have proposed that elements of attachment relationships emerge in these friendships and that older adolescent and adult peer relationships, particularly with romantic partners, can be conceptualized as attachment relationships (Fraley \& Shaver, 2000; Hazan \& Shaver, 1994; Hazan \& Zeifman, 1994; Weiss, 1986). Hazan and Shaver have developed a model for how attachment relationships are broadened to include peers. In terms of proximity seeking, children begin to spend more time with peers than parents. Relationships are usually developed in the context of close physical proximity (Hazan\&Shaver), although this need for proximity decreases over time. It is hypothesized that the increasing predictability of the peer's behavior and availability relaxes the need for close physical contact as the individual incorporates the peer's behavior into the internal working model and feels secure even when not in his or her presence (Crowell\&Waters, 1994). In late childhood and early adolescence, support and safe haven functions are often sought from peers and attachment in adolescence centers on this felt security, (Sroufe \& Waters, 1977) as opposed to proximity seeking (Schneider \& Younger, 1996).

Once the peer has consistently proven to be responsive in times of distress, the secure base phenomenon manifests itself by the internalization of the knowledge that the peer will be available in times of need (Hazan\&Shaver). Within this model, parents are never relinquished as attachment figures. Rather, they move down in the attachment hierarchy (Hazan\&Shaver, 1994; Hazan \& Zeifman, 1994) until, eventually, a romantic partner replaces the 
parent as the primary attachment figure in adulthood (Furman \& Wehner, 1994; Hazan \& Zeifman, 1994). The romantic partner not only becomes an attachment figure, but this relationship embodies the functioning of the caregiving, affiliative, and sexual behavioral systems (Furman \& Wehner, 1994, 1997). Furman and Wehner have proposed that major changes in the attachment hierarchy occur in adolescence, prior to the emergence of romantic partners as significant figures in late adolescence and early adulthood.

There is some empirical support for the hypothesis that attachment components shift from parents to peers, although several unanswered questions remain. Hazan and Zeifman (1994) tested the transfer of attachment hypothesis with 6- to 17-year-old children. The children and adolescents in their study were more peer- than parent-oriented in proximity seeking. Between ages 8 and 14, most children turned to friends for comfort and emotional support, thereby transferring the safe haven function from parents to peers. In late adolescence, secure base functions were still primarily with parents, although $41 \%$ of the sample reported a peer as the primary attachment figure.

In the majority of these cases, the specified peer was a romantic partner. The timing of these changes is consistent with reports of young adults, who have indicated that their adolescent romantic relationships were sources of companionship and enjoyment, whereby later relationships incorporated more elements of trust and support (Shulman \& Kipnis, 2001). The Hazan and Zeifman study did not allow for the precise pinpointing of differences in parents and peers as attachment figures because it used a relatively small sample size of 100 and included children across a wide age range.

The broadening of attachment functions from parents to peers has also been examined with older adolescents and young adults (Fraley \& Davis, 1997; Freeman \& Brown, 2001). Fraley and Davis found that most young adults selected peers to fulfill proximity-seeking needs, but only half of their sample selected peers to fulfill safe haven functions of attachment, and the majority indicated that parents fulfilled secure base needs. The high school juniors and seniors in Freeman and Brown's study were equally likely to identify parents and peers as primary attachment figures. Although these studies lend some support for the hypothesis that attachment components shift from parents to peers, it appears that parents still fulfill the role of the primary attachment figure in late adolescence and early adulthood.

\section{Predictors of the Introduction of Peers in the Attachment Hierarchy}

Theory suggests that an individual with a secure attachment to a parent will use this relationship as a secure base to explore other relationships and will develop an internal working model of self, others, and relationships as warm and secure, leading to success in relationships. Secure attachment to parents has been shown to lead to success in interpersonal functioning (Black \& McCartney, 1997; Elicker et al., 1992; Rice, 1990), and adolescents who 
describe their parents as warm and accepting are more likely to indicate intimate relationships with best friends (Madden-Derdich, Estrada, Sales, Leonard, \& Updegraff, 2002).

Despite this theoretical and empirical support for the internal working model, there is increasing evidence to suggest that parent-adolescent relationships and friendships are unique and that some adolescents with insecure attachment relationships with parents may seek friends to fulfill these needs. The correlation between adolescent and adult attachment to parents and peers ranges from .15 to .31 across measures, indicating that these attachment relationships are related, yet the attachment system can also be unique for different relationships (Crowell et al., 1999). Furthermore, some studies have found that insecurely attached adolescents are more likely to seek romantic attachment relationships prematurely (Hazan \& Zeifman, 1994) and to select peers to fulfill attachment needs (Freeman \& Brown, 2001; Schneider \& Younger, 1996).

Both Fraley and Davis (1997) and Freeman and Brown (2001) extended the findings of Hazan and Zeifman (1994) by assessing the extent to which individual attachment styles and working models of relationships were associated with using peers as attachment figures. Fraley and Davis found that a secure working model of attachment was positively correlated with using a best friend as an attachment figure and that mutual caring and trust in the peer relationship was positively correlated with using the friend as an attachment figure. However, the relationship between the internal working model of attachment and elements of mutual caring and trust in the friendships were not strongly related. In Freeman and Brown's sample, more than $90 \%$ of individuals with secure parent attachments identified a parent as the primary attachment figure, whereas the large majority of adolescents with insecure attachment styles selected a peer as the primary attachment figure.

Given these complexities in perceptions of close relationships, Furman and Wehner $(1994,1997)$ have proposed the concept of views, which are conscious and unconscious perceptions of a particular relationship, the self, and the partner within this relationship. Although these views are shaped by past interactions and experiences in that relationship and other relationships, they differ from the internalworking model in that people have distinct views for each particular relationship. According to Furman andWehner, views can be assessed through self-report. Furman and colleagues have found that adolescents' views of friendships are consistent with their views of romantic relationships and parent-child relationships, whereas views of romantic partners and parent-adolescent relationships are inconsistent (Furman, Simon, Shaffer, \& Bouchey, 2002), suggesting that friendship is an important relationship that may serve as a link between the parent-child and later romantic relationships. 
Taken together, the aforementioned reviewillustrates the need to consider age differences in attachment relationships with parents and friends and the individual's views of the security of these relationships when studying the introduction of friends into the attachment hierarchy. When studying close relationships, it is also important to examine the ways in which males and females differ. An oft-cited sex difference in friendship is that girls consistently report more intimacy and self-disclosure in their friendships, with this difference being most pronounced in early adolescence (Berndt \& Perry, 1990; Buhrmester, 1990). Despite this consistent finding, sex differences have generally not been found in attachment research (Ainsworth, 1991; Hazan \& Shaver, 1994), with the exception of a few studies conducted with older adolescents where females scored higher than males on measures of peer attachment (Armsden \& Greenberg, 1987; Paterson, Field, \& Pryor, 1994). Given the inconsistencies of past research, it is important to examine potential sex differences when studying close relationships, particularly with measures developed to assess the construct of attachment.

\section{Present Study}

The onset of early adolescence, sex differences, and views of attachment relationships are all potential contributors to the introduction of friends into the attachment hierarchy. The majority of studies examining parent and peer attachment have focused on older adolescents and adults. Therefore, there is a need to study differences in parent and peer relationships from an attachment framework and to pinpoint more specifically the timing of the introduction of peers into the attachment hierarchy for individuals in late childhood and early adolescence. In addition, research is needed to identify the role of views of parent and peer attachments in predicting the introduction of friends into the attachment hierarchy.

This study examined child and early adolescent close relationships with parents and friends, using attachment theory as a framework. Fourth, sixth, and eighth grade students were studied, with these grades representing children in late childhood, younger early adolescents, and older early adolescents, respectively. These three age groups were selected so that specific comparisons could be made concerning differences in parent and peer attachment within this period of rapid changes. Two measures of attachment were used to explore the changes in the parent and peer attachment relationships and the possible shifting of attachment functions from parent to peer. The aims of the study were (a) to investigate grade, sex, and the interaction of grade and sex differences in views of attachment relationships with parents and peers; (b) to more specifically explore and validate the Hazan and Shaver (1987) model for the shifting of the attachment components of proximity seeking, safe haven, and secure base from parent to peer in middle childhood and early adolescence; and (c) to examine whether views of attachment security with parents and peers, grade, and sex predict the choice of parents or peers to fulfill attachment functions of proximity seeking, safe 
haven, and secure base.

\section{METHOD}

\section{Participants}

Participants consisted of 303 children $(n=144$ male, 159 female) from three elementary and three middle schools in a school district in a suburban area on the outskirts of a southeastern city. Census tract data from the school district approximates the U.S. population in most demographic categories. Children in the fourth grade $(\mathrm{n}=103)$ had a mean age of $9.61(\mathrm{SD}=.57)$, sixth grade students $(\mathrm{n}=103)$ had a mean age of $11.67(\mathrm{SD}=.71)$, and eighth graders $(n=97)$ had a mean age of $13.58(\mathrm{SD}=.64)$.

\section{Measures}

To investigate the hypotheses, an extensive literature search was conducted to identify measures (a) that assessed parent and peer relationships, (b) that were based on the theoretical construct of attachment, and (c) that were appropriate for children and adolescents from the ages of 9 to 15 . In addition, several leaders in the field, such as C. Fraley (personal communication,October 6, 1999), W. Furman (personal communication, October 12, 1999), C. Hazan (personal communication, September 23, 1999), and Everett Waters (personal communication, October 6, 1999) were consulted for their opinions of the most appropriate measures to use for this study.

Attachment to parents and peers: People in My Life (Cook, Greenberg, \& Kusche, 1995). Child and early adolescent attachment relationships with parents and peers were assessed with the Parent and Peer Scales of People in My Life. This self-report measure of attachment assesses children's relationships with their parents, peers, schools, and neighborhoods. It is intended for use with children and early adolescents, and it was developed from a sample of 320 students with a mean age of 11 . Each item is rated on a 4-point scale: "Almost Never or Never True" (1 point), "Sometimes True" (2 points), "Often True" (3 points), and "Almost Always or Always True" (4 points). People in My Life is a downward extension of Armsden and Greenberg's (1987) Inventory of Parent and Peer Attachment, which was originally developed through factor analysis with a college student sample to tap behavioral elements of adolescent attachment and affectively toned cognitive expectancies, suggestive of the internal working models of attachment to parents and close friends.

The parent scale consists of 20 items, 10 of which assess trust, 5 items that measure communication, and 5 items that measure alienation. The reliability coefficient for the parent scale is .88 , and alpha coefficients for the subscales range from .65 for alienation to .87 for trust. The peer scale consists of 27 items, 10 of which assess trust, 5 items that measure communication, 7 items that assess alienation, and 3 items that measure delinquency. Items from each 
scale are summed and can be divided by the number of items to obtain a mean between 1 and 4 . Adding the trust and communication scores and subtracting the alienation score derive the parent total scale, and scores can range from -

2 to 7 . Adding the trust and communication scores and subtracting the alienation and delinquency scores calculate the peer total scale, and scores can range from -6 to 6 . The reliability coefficient for the peer scale is .90 , with subscale coefficients ranging from .68 for delinquency to .90 for trust. The parent scale and the peer scale of People in My Life have differential influences on child outcome measures, including internalizing and externalizing behaviors, peer competence, and ability to handle stress (Cook et al., 1995). Transfer of attachment: The WHOTO (Fraley \& Davis, 1997). Fraley and Davis's (1997) revised version of theWHOTOwas used to assess the transfer of attachment functions from parents to peers. This measure assesses the three core components of attachment relationships (i.e., proximity seeking, safe haven, and secure base) by asking six questions about whom in the participant's life best serves each of the functions. Two items assess each of the three components, resulting in a total of six questions. The original version of the WHOTO was constructed according to the assumption that attachment components would be functionally and psychologically equivalent to the behavioral manifestations of attachment observed in infants (Hazan \& Zeifman, 1994). Examples include asking respondents who they like to spend time with for proximity seeking and who they can always count on for secure base. Each item is scored 0 for parent or 1 for peer.

The WHOTO and related versions have been used to study the transfer of attachment for children as young as 6 years old (Hazan\&Zeifman, 1994) and for older adolescents and adults (Fraley \& Davis, 1997; Trinke \&

Bartholomew, 1997). According to C. Hazan (personal communication, September $23,1999)$, the original developer of the instrument, the adaptation used by Fraley and Davis (1997) was suitable for the age range in the current study. To simplify administration for younger populations, participants in this study were asked to choose one preferred person for each question, as Hazan and Zeifman (1994) did with the children and adolescents in their sample. Participants were asked to circle their choice for each answer instead of asking them to write in the name of a person who best fulfills each function. The choices given were parent, grandparent, sibling, best friend, romantic friend, or other.

\section{Procedure}

With district and school permission, fourth grade teachers in three elementary schools and sixth and eighth grade teachers in three middle schools were contacted to explain the study. The principal investigator introduced the study to the children and adolescents in their classrooms and gave them informed consent forms to give to their parents. Both parental consent and child assent was obtained from $66 \%$ of fourth graders, $27 \%$ of sixth graders, and $28 \%$ of eighth graders. It should be noted that this response rate was somewhat lower than that reported in similar studies, likely because other 
investigators have used monetary incentives (Freeman \& Brown, 2001; Furman et al., 2002) or sent letters directly to parents, instead of giving informed consent forms to the students.

Students whose parents gave consent to participate in the study were administered the attachment measures and a brief demographic information sheet in groups ranging from approximately 10 to 25 students. The measures were administered in counterbalanced order to each group of participants. The researcher read the instructions and each item of every measure to the fourth grade students and read only the instructions to the sixth and eighth graders.

To minimize the confound of overlapping ages between participants in the three grades, students who did not report their age or who were old for their grade were eliminated ( $\mathrm{n}=5$ fourth graders, $\mathrm{n}=9$ sixth graders, and $\mathrm{n}=8$ eighth graders), resulting in a sample of 279. The final sample therefore consisted of 98 fourth graders, ranging in age from 8 to 10 , with a mean age of $9.58(\mathrm{SD}=.54) ; 92$ sixth graders, ranging in age from 11 to 12 , with a mean age of $11.5(\mathrm{SD}=.50)$; and 89 eighth graders, ranging in age from 13 to 14 , with a mean age of $13.45(\mathrm{SD}=.50)$. Of the sample, $64 \%$ of the sample was Caucasian, $32 \%$ was African American, $1 \%$ was Hispanic or Latino, $1 \%$ was Asian, and $2 \%$ classified themselves as other.

\section{RESULTS}

To address the question of whether attachment functions with parents and peers differ as a function of sex and grade, a $2 \times 3(\operatorname{sex} \times$ grade) multivariate analysis of variance (MANOVA) was conducted, with the parent total and parent subscales (trust, communication, alienation) and peer total and peer subscales (trust, communication, alienation, delinquency) of People in My Life serving as dependent variables. TheMANOVA yielded significant main effects for grade, $\mathrm{F}(14,550)=6.01, \mathrm{p}=.00, \chi^{2}=.13$, and sex, $\mathrm{F}(7,275)=$ $2.43, \mathrm{p}=.02, \chi 2=.06$, but there were no significant interactions between grade and sex, $\mathrm{F}(14,550)=1.41$, ns.

There were significant grade differences in the parent total, parent trust, parent communication, peer trust, and peer delinquency scales of People in My Life (see Table 1). Post-hoc testing, using Tukey's studentized range, revealed that fourth graders reported significantly greater attachment to parents scores than eighth graders, but there were no differences between any of the other grade comparisons. Post-hoc comparisons showed that there were significant differences in parent trust between all three grades, with fourth graders reporting greater trust of parents than both sixth graders and eighth graders and sixth graders reporting greater trust of parents than eighth graders. Fourth graders also had higher scores on parent communication than both sixth graders and eighth graders, although there was no difference between scores for sixth and eighth graders. The peer trust subscale differed 
significantly by grade, with post-hoc comparisons indicating that fourth graders reported higher levels of trust than eighth graders. In addition, there were significant differences in Peer Delinquency, with eighth graders reporting more delinquent behaviors with friends than either sixth graders or fourth graders. As shown in Table 2, there were no significant sex differences in parent attachment, although several sex differences emerged for attachment to peers. Females scored higher than males on attachment to peers. Females also reported greater trust of and communication with peers than did males. To explore and validate the Hazan and Shaver (1987) model of the shifting of attachment components from parent to peer, fourth, sixth, and eighth graders'responses to all items on theWHOTOwere calculated (see Table 3). Parents and best friends were selected more frequently than grandparents or romantic friends, although this varied. For example, nearly $25 \%$ of eighth graders selected romantic friends for proximity seeking, although this percentage decreased markedly for safe haven and secure base. Responses were then categorized as either parent, which included parent or grandparent, peer, which included best friend or romantic friend, or other (e.g., sibling, other relative, pet) and chi-square analyses were conducted to assess grade differences in proximity seeking, safe haven, and secure base items on theWHOTO. As grade increased, participants tended to seek less proximity from parents and more from peers. Grade was significant for the first proximity-seeking item, "Who is the person you most like to spend time with?" $(\chi 2=49.27, p>$ $.001)$ and approached significance for the second item, "Who is the person you do not like to be away from?" $(\chi 2=8.86, \mathrm{p}=.06)$. Table 3 demonstrates a similar trend for the safe haven item addressing emotional support, with older participants turning to parents less and peers more when they are upset, as opposed to fourth graders, who turned more to parents than peers, $\chi 2=$ $27.43, p>.001$. However, the second safe haven item regarding advice-seek-

TABLE 1: Means, Standard Deviations, and Univariate Statistics for People in My Life Scales by Grade

Grade

Fourth Sixth Eighth

$(\mathrm{n}=98)(\mathrm{n}=92)(\mathrm{n}=89)$

Scale M SD M SD M SD F $(2,281) 2$

Parent total $5.211 .26 \mathrm{a} 4.771 .424 .391 .677 .40^{* *} .05$

Parent trust 3.71 0.37a,b 3.54 0.49a $3.360 .5712 .34 * * .08$

Parent

communication $3.420 .61 \mathrm{a}, \mathrm{b} 3.080 .672 .910 .7215 .27^{* *} .10$

Parent alienation 1.920 .751 .850 .591 .880 .620 .55 .00

Peer total 4.741 .414 .481 .364 .611 .571 .05 .05

Peer trust 3.48 0.60a $3.330 .573 .270 .553 .77^{*} .03$

Peer

communication $3.030 .782 .870 .683 .020 .71 \quad 1.43 .01$

Peer alienation 1.770 .541 .710 .541 .680 .590 .47 .00

Peer delinquency 1.100 .28 a 1.190 .43 a $1.550 .7120 .31^{* *} .13$ 
a. Mean differs from eighth grade mean at $p>.05$.

b. Mean differs from sixth grade mean at $p>.05$.

$* \mathrm{p}>.05 . * * \mathrm{p}>.01$.

ing did not differ as a function of grade. Neither of the items assessing the secure base function of attachment yielded significant grade differences. The majority of participants, regardless of grade, relied on parents more than peers to fulfill these needs.

To enhance the reliability of the WHOTO, the subscales of proximity seeking, safe haven, and secure base were only coded if participants selected the same person (peer or parent) for both items in the subscale. The number of participants who selected the same person for both items in each subscale were as follows: 151 (56 fourth graders, 49 sixth graders, and 46 eighth graders) for proximity seeking, 158 (59 fourth graders, 49 sixth graders, and 50 eighth graders) for safe haven, and 183 (69 fourth graders, 58 sixth graders, and 56 eighth graders) for secure base.

As shown in Figure 1, there were significant grade differences in whom participants selected to fulfill the functions of proximity seeking, $\chi 2(2)=$ $30.09, p>.001$ and safe haven, $\chi 2(2)=20.11, p>.001$, with eighth graders selecting peers more often than fourth and sixth graders. However, further analyses revealed a significant difference only for the safe haven question addressing emotional support, $\chi 2(4)=24.25, \mathrm{p}>.001$ and not for the item regarding advice-seeking, $\chi 2(4)=7.84$, ns. Secure base functions did not differ by grade, $\chi 2(2)=.33$ and the large majority of respondents in all grades selected parents to fulfill these needs.

To examine the variables that predict to whom children and adolescents turn to fulfill attachment functions, logistic regression analyses were con-

TABLE 2: Means, Standard Deviations, and Univariate Statistics for People in My Life Scales by Gender

Gender

Male Female

$(\mathrm{n}=135)(\mathrm{n}=152)$

Scale M SD M SD F $(1,281) 2$

Parent total 4.811 .364 .791 .590 .03 .00

Parent trust 3.520 .503 .560 .490 .36 .00

Parent communication 3.130 .673 .140 .720 .06 .00

Parent alienation 1.850 .621 .900 .690 .64 .00

Peer total $4.391 .494 .791 .405 .93 * .02$

Peer trust $3.280 .633 .420 .544 .72 * .02$

Peer communication $2.810 .733 .120 .6913 .53 * * .05$

Peer alienation 1.700 .581 .750 .540 .38 .00

Peer delinquency 1.300 .531 .270 .550 .44 .00

$* \mathrm{p}>.05 . * * \mathrm{p}>.01$. 
TABLE 3: Targets of Attachment Functions on the WHOTO by Grade

WHOTO Attachment-

Related Questions Fourth Sixth Eighth

and Targets $(n=98)(n=100)(n=89)$

Who is the person you most like to

spend time with? (Prox)

Parent 483211

Grandparent 13105

Best friend 144241

Romantic friend 9523

Sibling 589

Other 930

Who is person you do not like to be away from? (Prox)

Parent 504633

Grandparent 10128

Best friend 151417

Romantic friend 141422

Sibling 5116

Other 433

Who is the person you want to be with when you are

feeling upset or down? (Safe)

Parent 543016

Grandparent 111812

Best friend 192736

Romantic friend 51714

Sibling 647

Other 344

Who is the person you would count on for advice?

(Safe)

Parent 524133

Grandparent 161815

Best friend 182227

Romantic friend 413

Sibling 4137

Other 444

Who is the person you would tell first if you achieved something good? (Secure)

Parent 666058

Grandparent 7116

Best friend 152115

Romantic friend 534

Sibling 346

Other 200

ducted, with grade, sex, parent total scale, and peer total scale of People inMy 
Life serving as predictor variables. Three separate logistic regression analyses were conducted for the categorical variables of (a) proximity seeking, (b) safe haven, and (c) secure base. Each of these variables was dichotomized according to whether the participant selected the parent (coded 0 ) or the peer (coded 1) to fulfill each function.

All the logistic regression models were significant, indicating that the models fit the data well for participants selecting peers or parents to fulfill needs for proximity seeking, $\chi 2(5)=65.85, \mathrm{p}>.001$; safe haven, $\chi 2(5)=$ $44.13, p>.001$; and secure base, $\chi 2(5)=34.98, p>.001$. To assess the influence of each predictor variable on the criterion variables in logistic regression, odds ratios were used. Odds ratios range from 0 to infinity, with 1 indicating no difference in the predictor variable on the criterion variable. Because of this asymmetry, the same odds, but in opposite directions, may appear different (Pedhazur, 1997). In this study, the odds ratio indicated changes in the likelihood of identifying the peer as fulfilling the attachment need per one unit of change in the predictor variable. Because three separate regression analyses were conducted, the alpha level was set at .02 to minimize the likelihood of Type I errors.

As shown in Table 4, several factors predicted whether participants selected a parent or peer as the person to fulfill proximity-seeking needs. Grade was a significant predictor, with eighth graders being 11.34 times more likely than fourth graders to turn to a peer for proximity seeking. Sex was also significant, with females being less likely than males to turn to peers for proximity seeking. Security of attachment to parents and peers predicted the likelihood of participants selecting peers as the primary source of proximity seeking. Participants with less secure attachment to parents were more likely to turn to peers, and those with more secure attachment to peers were more likely to turn to peers.

Who is the person you can always count on? (Secure)

Parent 574741

Grandparent 91513

Best friend 232523

Romantic friend 355

Sibling 264

Other 423

NOTE: Prox $=$ Proximity seeking. Safe $=$ Safe haven. Secure $=$ Secure base .

TABLE 3 (continued)

WHOTO Attachment-

Related Questions Fourth Sixth Eighth

and Targets $(\mathrm{n}=98)(\mathrm{n}=100)(\mathrm{n}=89)$

Figure 1: Persons selected to fulfill attachment functions by grade. Proximity Seeking 
70

80

90

Fourth Sixth Eighth

Grade

Percentage

Parent

Peer

Safe Haven

0

20

40

60

80

100

Fourth Sixth Eighth

Grade

Percentage

Parent

Peer

Secure Base

0

10

20

30

40

50

60

70

80

90

Fourth Sixth Eighth

Grade

Percentage

Parent

Peer

There were similar trends in the logistic regression model for safe haven, except sex did not affect the likelihood of participants selecting a peer to fulfill 
this attachment function. As with proximity seeking, grade was a significant predictor, with eighth graders being 7.12 times more likely than fourth graders to seek peers rather than parents to fulfill safe haven functions. Security of attachment to parents was inversely related to turning to peers as safe havens, whereas attachment to peerswas a positive predictor. For each unit of change (i.e., 1 point on the 13-point scale) in the peer total scale of People In My Life, participants were 1.72 times more likely to turn to peers for safe haven functions.

TABLE 4: Logistic Regression Models for Effect of Grade, Sex, and Parent and Peer Attachment Security on Selection of Parent or Peer for Attachment

Functions

Criterion Predictor Wald 2 df Odds ratio

Parent-peera proximity seeking $(\mathrm{n}=151)$

Grade 20.54** 2

Grade (6th compared to 4th) 0.631 .6111 .89

Grade (8th compared to 4th) $2.4319 .56^{* *} 111.34$

Sexb $-1.075 .75 * 10.34$

Parent attachment security $-0.8218 .57 * * 10.44$

Peer attachment security $0.7515 .86^{* *} 12.12$

Parent-peera safe haven $(\mathrm{n}=158)$

Grade $14.80 * * 2$

Grade (6th compared to 4th) 0.892 .6012 .43

Grade (8th compared to 4th) $1.9614 .26 * * 17.12$

Sexb 0.360 .6911 .43

Parent attachment security $-0.7817 .30 * * 10.46$

Peer attachment security $0.549 .07 * 11.72$

Parent-peera secure base $(\mathrm{n}=183)$

Grade 0.392

Grade (6th compared to 4th) -0.280 .2910 .75$

Grade (8th compared to 4th) - .290 .2910 .75

Sexb-1.02 5.28* 10.36

Parent attachment security $-0.8923 .21 * * 10.41$

Peer attachment security $0.7211 .75^{* *} 12.05$

a. Parent was coded 0 and peer was coded 1 .

b. Male was coded 0 and female was coded 1 .

$* \mathrm{p}>.05 . *{ }^{*} \mathrm{p}>.01$.

A different trend emerged in terms of secure base, where grade was not a significant predictor. Sex significantly predicted the likelihood of turning to a peer for this function, with females being less likely than males to select peers. As with the other two attachment functions, security of attachment to parents was inversely related to selecting peers, whereas security of attachment to peerswas a positive predictor of this trend. Each unit of change in the People in My Life peer total scale predicted the likelihood of that participant being 2.05 times more likely to turn to peers to fulfill secure base functions. 


\section{DISCUSSION}

This study sought to enhance our knowledge about child and early adolescent attachment to parents and peers. Although ample theoretical evidence exists regarding these issues, most empirical studies focus on infants, young children, and adults, leaving the critical transition from late childhood to early adolescence largely unexplored. The results of this study indicate that early adolescents, as compared to children in late childhood, report less trust and communication with parents, and begin to turn to peers to fulfill attachment needs of proximity seeking and safe haven. However, parents continue to provide the secure base from which early adolescents explore other relationships.

Some grade differences in attachment to parents and peers were found, with fourth graders reporting more secure attachment to parents than eighth graders. These findings suggest that there are differences in attachment between late childhood and older early adolescence. More specific comparisons showed that fourth graders reported more trust and communication than both sixth graders and eighth graders. In addition, sixth graders reported more trust of parents than did eighth graders. Early adolescents' tendency to rate relationships with parents as less trusting and less communicative is consistent with relevant literature, which indicates that the onset of adolescence is accompanied by spending less time with parents and perceiving parents as less supportive (Ammaniti et al., 2000; Paikoff \& Brooks-Gunn, 1991). It should be noted that there were no significant grade differences in parent alienation, and as suggested by Arnett (1999), satisfaction with these relationships may be maintained, despite the greater conflict with and distance from parents during adolescence. In addition, fourth graders reported trusting peers more than eighth graders. This finding, coupled with the parallel pattern with respect to trust of parents, suggests that older early adolescents may be more discerning than children. As thinking becomes more complex, abstract, and differentiated (Damon, 1983) and early adolescents become more autonomous and concerned with themselves, they may begin to view close relationships in more critical terms, such as not being as trusting as younger children of parents and peers. In addition, peer delinquency differed as a function of grade, with eighth graders reporting significantly more delinquency than fourth and sixth graders, suggesting that some adolescents become more susceptible to deviant peer influence, and may be more likely to engage in behaviors such as cheating and drinking.

There were no sex differences in attachment to parents, as theory and past research has suggested (Ainsworth, 1991). However, there were sex differences in attachment to peers, with females reporting more trust, communication, and overall attachment to peers than males. Past studies have not tended to find sex differences in attachment for infants (Ainsworth; Ainsworth, Blehar, Waters, \& Wall, 1978), older adolescents, and adults (Hazan \& 
Shaver, 1994).

Why, then, would the present study have uncovered sex differences in attachment to peers? As Ainsworth (1991) has suggested, sex differences may have yet to be discovered, and the results of the present study may be a starting point for exploring these differences. The friendship literature is replete with studies demonstrating that girls report more intimacy and selfdisclosure than boys in their friendships (Belle, 1989; Furman \& Buhrmester, 1992), particularly in early adolescence (Berndt \& Perry, 1990). Therefore, early adolescence may represent a critical time period for the emergence of sex differences in attachment. Alternatively, it is possible that the sex differences found in this study reflected the specific relationship qualities of communication and verbal intimacy.

Transitions in attachment relationships were also examined by asking participants to select one person towhom theywould turn to meet various attachment needs. Early adolescents demonstrated a tendency to seek proximity from peers rather than parents, whereas children in late childhood tended to spend more time with parents than peers. This difference was particularly pronounced for older early adolescents, with eighth graders selecting both best friends and romantic friends to fulfill proximity-seeking needs far more than children in late childhood. These findings are more specific in pinpointing a possible critical time for the introduction of this attachment component in friendship, in comparison to the more general findings in past research (Hazan \& Zeifman, 1994).

The second attachment function, safe haven, also showed pronounced differences between older early adolescents, who reported turning to peers more than did individuals in late childhood and younger early adolescence. This was true for the safe haven item of the WHOTO assessing emotional support but not for the item measuring advice-seeking. These findings highlight the important and complementary roles of peers and parents; Intimacy and emotional disclosure is critical in friendships (Berndt, 1989; Berndt \& Perry, 1990), and early adolescents seek the approval and guidance of their parents for more significant life issues (Savin-Williams \& Berndt, 1990). There were no grade differences in the secure base function of attachment, and more than $75 \%$ of the sample identified a parent as the person who could always be counted on. This was not surprising, especially in light of findings that older adolescents and adults even report that parents continue to serve the secure base function (Fraley\&Davis, 1997; Hazan\&Zeifman, 1994; Trinke $\&$ Bartholomew, 1997). Taken together, findings from this and other research suggest that, although peers become more prominent in early adolescents' social networks, friendships are not likely to become full-blown attachment relationships during this time of life. Rather, a long-term close friend, most often a romantic partner, may rise to the top of the attachment hierarchy in adulthood (Fraley\&Davis, 1997; Hazan\&Shaver, 1994; Hazan\&Zeifman, 
1994) or under certain circumstances, such as when a parent is no longer living.

\section{Predictors of the Introduction of Friends into the Attachment Hierarchy}

As detailed above, gradewas a significant predictor of whom one chose to fulfill attachment needs. In addition, regression results indicated that sexwas a significant predictor, with females being less likely than males to select peers for proximity seeking and secure base functions, although there were no sex differences for safe haven.

Views of attachments to parents and peers also predicted the selection of peers to fulfill attachment functions. Participants who viewed attachment to parents as less secure were more likely to turn to peers for proximity seeking, safe haven, and secure base functions. These findings are consistent with studies that have found adolescents with insecure attachments to parents to view their peer relationships as secure (Furman et al., 2002) and to select peers to fulfill attachment needs (Freeman \& Brown, 2001; Schneider \& Younger, 1996). In addition, a recent longitudinal study found a lack of continuity in attachment from infancy to adulthood for a high-risk sample (Weinfield, Sroufe, \&Egeland, 2000). These findings raise interesting questions about the validity of the construct of the internal working model. More specifically, it is possible that individuals with less secure parental attachments, instead of being destined to have insecure relationships with others, may actually compensate for this by seeking close relationships with others, such as trusted peers.

Another possible explanation for this finding is that children and early adolescents are experiencing normal and adaptive transformations in their relationships with parents and peers. Therefore, views of relationships with parents as less positive may reflect children's and early adolescents' decreased dependency on parents and increased conflict, which could signal the emergence of close, yet autonomous (i.e., individuated) relationships with parents (Collins \& Repinski, 1994; Delaney, 1996). Adolescents may have built up a more consistent internal working model of parents as secure attachment figures, where parents may not be used as regularly as peers to fulfill needs. In this model, parents and peers serve complementary, as opposed to compensatory, functions (Hunter \& Youniss, 1982; Paterson et al., 1994).

\section{Limitations of Study}

There are some limitations of the current study. First, the use of a crosssectional design does not allow us to know for certain whether differences in attachment relationships are related to age differences as opposed to some other difference in the cohorts studied. The use of longitudinal designs in future research would allow for better inferences regarding individual patterns of development in attachment relationships. Second, conducting 
attachment research with children in this age group is challenging because of the lack of well-validated measures. Although People in My Life and the WHOTO were judged to be the best instruments available, there are some notable limitations of these tools. Both of the instruments are paper-andpencil measures, which may not be as comprehensive as interviews in their assessment of unconscious, integrated working models of attachment (Furman \& Wehner, 1994, 1997).

People in My Life assesses various aspects of attachment to parents and peers, in general, as opposed to asking about a child's mother, father, and individual friends. Recent research has indicated that attachment relationships with mothers and fathers are differentially related to outcomes. For example, Simons, Paternite, and Shore (2001) found that attachment to mothers but not with fathers was predictive of adolescent self-esteem, views of others, and aggression. Marcus and Betzer (1996) also found attachment to fathers to be the strongest predictor of antisocial behavior. By assessing relationships with parents and peers, in general, the finer distinctions in these individual relationships were not explored in this study. Using the WHOTO to study the transfer of attachment from parent to peer also presented some limitations. Results of this study suggest that this instrument may not have accurately assessed the three functions of attachment, given the substantial amount of variability among items that were supposed to comprise the safe haven function of attachment.

\section{Future Research}

The area of attachment relationships in late childhood and early adolescence is understudied, leaving many opportunities for future research. There is a critical need to develop reliable, valid instruments that measure the quality of individual attachment relationships (e.g., mother, father, best friend) for this age group. The Strange Situation procedure (Ainsworth et al., 1978) has been well validated for assessing attachment in infants, and a number of instruments have been developed for individuals in late adolescence and adulthood (for reviews, see Crowell et al., 1999; Lyddon, Bradford, \& Nelson, 1993). Developing psychometrically sound assessment tools for late childhood and early adolescence will be necessary to advance our knowledge of the role of attachment in the parent and peer relationships for this age group. There have been some promising measures developed recently, such as the Behavioral Systems Questionnaire (Furman \&Wehner, 1999), which measures adolescents' self-perceptions of relational styles for relationships with parents, friends, and romantic partners. In addition, recent measures developed to assess secure base behavior in relationships (Crowell et al., 2002) may serve as models for the development of measures to assess attachment for children and adolescents.

Another area to be investigated in future research is children's and early adolescents' relationships with multiple attachment figures. Examining relationships 
with each attachment figure (e.g., mother, father, same-sex friend, romantic friend) may enrich our understanding of the multiple relationships integral to development. This would also be appropriate for studying children and adolescents from diverse family structures and different ethnic and cultural backgrounds, who may have close relationships with a number of people besides biological parents and close friends.

Last, a natural extension of this research would be to examine the broadening of attachment from parent or same-sex peer to romantic partner. Longitudinal studies may be especially useful in examining the developmental pathways from infancy to adulthood for shifts in attachment. Specific questions of this research may focus the chronology of the shift of attachment and what variables may predict the transfer of attachment from parent to peer to romantic partner. For example, the stability and level of intimacy in these relationships should be considered. Variables such as sex, ethnic and cultural background, and stressful life events may contribute to the shifting of attachment functions. Further study of the possible compensatory or protective function of friends for individuals with insecure parental attachments is also needed.

\section{Implications for Practice}

Findings from this study have several important implications for applied practice and suggest that the transition from late childhood to early adolescence is critical in negotiating close relationships. Collectively, findings from this study fit Hazan and Shaver's (1994) model describing the progression of the broadening of the attachment hierarchy to include peers and indicate some substantial differences in these relationships for individuals in early adolescence versus those in late childhood. On entry into early adolescence, peers becomecentral sources of companionship and emotional support, and thismay be especially true for youths with less secure attachments to parents. Close peer relationships relate to positive outcomes for youth (Bukowski et al., 1993; Reis \& Shaver, 1988), suggesting that the development of these relationships should be encouraged. Schools are ideal settings in which to promote resiliency and competency in children (Doll\&Lyon, 1998), and efforts should be made to facilitate the development of close peer relationships. Teaching methods such as peer tutoring, which achieves positive academic outcomes but also facilitates social relationships and increases cooperation among children across racial, ethnic, and disability groups (Walker, Greenwood, \& Terry, 1994) could be used.

This study also suggested that early adolescents' relationships with peers closely resemble attachment relationships in respect to proximity-seeking and safe haven functions but that parents continue to provide the secure base from which early adolescents explore their autonomy. Therefore, both relationships remain critically important to early adolescents, with peers and parents serving different yet complementary roles (Hunter \& Youniss, 1982; 
Paterson et al., 1994). Educators and mental health practitioners who work with early adolescents and their families should support the role of friends as providers of emotional support and advice in the realms of interpersonal relationships, leisure time, and emotional conflict, and to value the contributions of parents as providers of information and support regarding educational and long-term goals. In addition, individuals with insecure attachments to parents may benefit from having close friendships in which they can feel safe to explore feelings and seek advice.

\section{REFERENCES}

Ainsworth,M. D. S. (1989). Attachments beyond infancy. American Psychologist, 44, 709-716. Ainsworth, M. D. S. (1991). Attachments and other affectional bonds across the life cycle. In C. M. Parkes, J. Stevenson-Hinde, \& P. Marris (Eds.), Attachment across the life cycle (pp. 33-51). New York: Tavistock/Routledge.

Ainsworth, M. D. S., Blehar, M. C.,Waters, E.,\&Wall, S. (1978).Patterns of attachment: A psychological study of the strange situation. Hillsdale, NJ: Lawrence Erlbaum.

Allen, J. P., \& Land, D. (1999). Attachment in adolescence. In J. Cassidy, \& P. R. Shaver (Eds.), Handbook of attachment: Theory, research, and clinical applications (pp. 319-335). New York: Guilford.

Ammaniti, M., van Ijzendoorn, M. H., Speranza, A. M.,\&Tambelli, R. (2000). Internalworking models of attachment during late childhood and early adolescence: An exploration of stability and change. Attachment and Human Development, 2, 328-346.

Armsden, G. C., \& Greenberg, M. T. (1987). The inventory of parent and peer attachment: Individual differences and their relationships to psychological well-being in adolescence. Journal of Youth and Adolescence, 16, 427-454.

Arnett, J. J. (1999). Adolescent storm and stress, reconsidered. American Psychologist, 54, 317326.

Bartholomew, K. (1993). From childhood to adult relationships: Attachment theory and research. In S. Duck (Ed.), Learning about relationships (pp. 30-62). Newbury Park, CA: Sage.

Belle, D. (1989). Gender differences in children's social networks and social supports. In D. Belle (Ed.), Children's social networks and social supports (pp. 173-188). New York: John Wiley and Sons.

Berndt, T. J. (1989). Obtaining support from friends during childhood and adolescence. In D. Belle (Ed.), Children's social networks and social support (pp. 308-331). New York: John Wiley and Sons.

Berndt,T. J.,\&Perry,T. B. (1990). Distinctive feature and effects of early adolescent friendships. In R. Montemayor, G. R. Adams, \& T. P. Gullotta (Eds.), From childhood to adolescence: A transitional period? (pp. 269-287). Newbury Park, CA: Sage.

Black, K. A., \& McCartney, K. (1997). Adolescent females' security with parents predicts the quality of peer interactions. Social Development, 6, 91-110.

Buhrmester, D. (1990). Intimacy of friendship, interpersonal competence, and adjustment during middle childhood and adolescence. Child Development, 61, 1101-1111.

Bukowski,W. M., Hoza, B., \& Boivin, M. (1993). Popularity, friendship, and emotional adjustment during early adolescence. In W. Damon (Series Ed.) \& B. Laurson (Vol. Ed.), New directions for child development (Vol. 60, pp. 23-37). San Francisco: Jossey-Bass. 
Collins, N. L., \& Feeney, B. C. (2000). A safe haven: An attachment theory perspective on support seeking and caregiving in intimate relationships. Journal of Personality and Social Psychology, 78, 1053-1073.

Collins, W. A., \& Repinski, D. J. (1994). Relationships during adolescence: Continuity and change in interpersonal perspective. In R. Montemayor, G. R. Adams,\&T. P. Gullotta (Eds.), Personal relationships during adolescence (pp. 7-36). Thousand Oaks, CA: Sage.

Cook, E. T., Greenberg, M. T., \& Kusche, C. A. (1995, March). People in my life: Attachment relationships in middle childhood. Poster Session presented at the Society for Research in Child Development, Indianapolis, Indiana.

Cotterell, J. L. (1992). The relation of attachments and support to adolescent well-being and school adjustment. Journal of Adolescent Research, 7, 28-42.

Crowell, J. A., Fraley, R. C., \& Shaver, P. R. (1999). Measurement of individual differences in adolescent and adult attachment. In J. Cassidy \& P. R. Shaver (Eds.), Handbook of attachment: Theory, research, and clinical applications (pp. 434-465). New York: Guilford.

Crowell, J. A., Treboux, D., Gao, Y., Fyffe, C., Pan, H., \&Waters, E. (2002). Assessing secure base behavior in adulthood: Development of a measure, links to adult attachment representations, and relations to couples' communication and reports of relationships. Developmental Psychology, 38, 679-693.

Crowell, J. A., \&Waters, E. (1994). Bowlby's theory grown up: The role of attachment in adult love relationships. Psychological Inquiry, 5, 31-34.

Damon, W. (1983). Social and personality development: Infancy through adolescence. New York: W. W. Norton.

Delaney, M. E. (1996). Across the transition to adolescence: Qualities of parent/adolescent relationships and adjustment. Journal of Early Adolescence, 16, 274-300.

Doll, B.,\&Lyon, M. A. (1998). Risk and resilience: Implications for the delivery of educational and mental health services in schools. School Psychology Review, 27, 348-363.

Elicker, J., Englund, M., \& Sroufe, L. A. (1992). Predicting peer competence and peer relationships in childhood from early parent-child relationships. In R. D. Parke\&G.W. Ladd (Eds.),

Family-peer relationships: Modes of linkage (pp. 77-106). Hillsdale, NJ: Lawrence

Erlbaum.

Fraley, R. C., \& Davis, K. E. (1997). Attachment formation and transfer in young adults' close friendships and romantic relationships. Personal Relationships, 4, 131-144.

Fraley, R. C., \& Shaver, P. R. (2000). Adult romantic attachment: Theoretical developments, emerging controversies, and unanswered questions. Review of General Psychology, 4, 132154.

Freeman, H., \& Brown, B. B. (2001). Primary attachment to parents and peers during adolescence: Differences by attachment style. Journal of Youth and Adolescence, 30, 653-674. Furman,W. (1993). Theory is not a four-letterword: Needed directions in the study of adolescent friendships. In B. Laursen (Ed.), Close friendships in adolescence: New directions for child development (Vol. 60, pp. 89-103). San Francisco: Jossey-Bass.

Furman, W., \& Buhrmester, D. (1992). Age and sex differences in perceptions of networks of personal relationships. Child Development, 63, 103-115.

Furman,W., Simon, V. A., Shaffer, L., \& Bouchey, H. A. (2002). Adolescents'working models and styles for relationships with parents, friends, and romantic partners. Child Development, $73,241-255$. 
Furman,W., \&Wehner, E. H. (1994). Romantic views: Toward a theory of adolescent romantic relationships. In R. Montemayor, G. R. Adams, \& T. P Gullotta (Eds.), Advances in adolescent development:An annual book series (Vol. 6, pp. 168-195). Thousand Oaks, CA: Sage.

Furman,W., \&Wehner, E. H. (1997). Adolescent romantic relationships: A developmental perspective.

In S. Shulman, \& W. A. Collins (Eds.), Romantic relationships in adolescence:

Developmental perspectives (pp. 21-36). San Francisco: Jossey-Bass.

Furman,W.,\&Wehner, E. A. (1999). The Behavioral Systems Questionnaire (Rev. ed.).

Unpublished measure, University of Denver, CO.

Hartup,W.W. (1989). Social relationships and their developmental significance. American Psychologist,

44, 120-126.

Hazan, C.,\&Shaver, P. R. (1987). Romantic love conceptualized as an attachment process.

Journal

of Personality and Social Psychology, 52, 511-524.

Hazan, C., \& Shaver, P. R. (1994). Attachment as an organizational framework for research on close relationships. Psychological Inquiry, 5, 1-22.

Hazan, C., \& Zeifman (1994). Sex and the psychological tether. In K. Bartholomew \& D. Perlman (Eds.), Attachment processes in adulthood. Advances in personal relationships (Vol. 5, pp. 151-177). London: Jessica Kingsley.

Hunter, F. T., \& Youniss, J. (1982). Changes in functions of three relationships during adolescence. Developmental Psychology, 18, 806-811.

Lyddon,W. J., Bradford, E., \& Nelson, J. P. (1993). Assessing adolescent and adult attachment: A review of current self-report measures. Journal of Counseling and Development, 71, 390395.

Madden-Derdich, D. A., Estrada, A. U., Sales, L. J., Leonard, S. A., \& Updegraff, K. A. (2002). Young adolescents'experiences with parents and friends: Exploring the connections. Family Relations, 51, 72-80.

Marcus, R. F., \& Betzer, P. D. S. (1996). Attachment and antisocial behavior in early adolescence. Journal of Early Adolescence, 16, 229-249.

Mounts, N. S. (2001). Young adolescents' perceptions of parental management of peer relationships. Journal of Early Adolescence, 21, 92-122.

Newcomb, A. F., \& Bagwell, C. L. (1995). Children's friendship relations: A meta-analytic review. Psychological Bulletin, 117, 306-347.

Paikoff, R. L.,\&Brooks-Gunn, J. (1991). Do parent-child relationships change during puberty? Psychological Bulletin, 110, 47-66.

Paterson, J. E., Field, J., \& Pryor, J. (1994). Adolescents' perceptions of their attachment relationships with their mothers, fathers, and friends. Journal of Youth and Adolescence, 23, 579-600.

Pedhazur, E. J. (1997). Multiple regression in behavioral research. Ft. Worth, TX: Harcourt Brace.

Reis, H. T.,\&Shaver, P. (1988). Intimacy as an interpersonal process. In S.W. Duck (Ed.), Handbook of personal relationships (pp. 367-389). New York: John Wiley and Sons.

Rice, K. G. (1990). Attachment in adolescence:Anarrative and meta-analytic review. Journal of Youth and Adolescence, 19, 511-538.

Savin-Williams, R. C.,\&Berndt, T. J. (1990). Friendship and peer relations. In S. S. Feldman\& 
G. R. Elliott (Eds.), At the threshold: The developing adolescent (pp. 277-307). Cambridge, MA: Harvard University Press.

Schneider, B. H., \& Younger, A. J. (1996). Adolescent-parent attachment and adolescents' relations with their peers: A closer look. Youth and Society, 28, 95-108.

Shulman, S., \& Kipnis, O. (2001). Adolescent romantic relationships: A look from the future. Journal of Adolescence, 24, 337-351.

Simons, K. J., Paternite, C. E., \& Shore, C. (2001). Quality of parent/adolescent attachment and aggression in young adolescents. Journal of Early Adolescence, 21, 182-194.

Sroufe, L. A., \& Waters, E. (1977). Attachment as an organizational construct. Child Development, 48, 1184-1199.

Sullivan, H. S. (1953). The interpersonal theory of psychiatry. New York: W. W. Norton. Trinke, S. J.,\&Bartholomew, K. (1997). Hierarchies of attachment relationships in young adulthood. Journal of Social and Personal Relationships, 14, 603-625.

Walker, D., Greenwood, C. R., \& Terry, B. (1994). Management of classroom disruptive behavior and academic performance problems. In L.W. Craighead,W. E. Craighead, E. E. Kazdin, \& M. J. Mahoney (Eds.), Cognitive and behavioral interventions: An empirical approach to mental health problems (pp. 215-234). Boston: Allyn and Bacon.

Weinfield, N. S., Sroufe, L. A., \& Egeland, B. (2000). Attachment from infancy to early adulthood in a high-risk sample: Continuity, discontinuity, and their correlates. Child Development, 71, 695-702.

Weiss, R. S. (1986). Continuities and transformation in social relationships from childhood to adolescence. In W. W. Hartup \& Z. Rubin (Eds.), Relationships and development (pp. 95110). Hillsdale, NJ: Lawrence Erlbaum.

Weiss, R. S. (1994). Is the attachment system of adults a development of Bowlby's attachment system of childhood? Psychological Inquiry, 5, 65-67. 